\title{
Novos táxons em Membracinae (Hemiptera, Membracidae) ${ }^{1}$
}

\author{
Antonio J. Creão-Duarte² \& Albino M. Sakakibara ${ }^{3,4}$
}

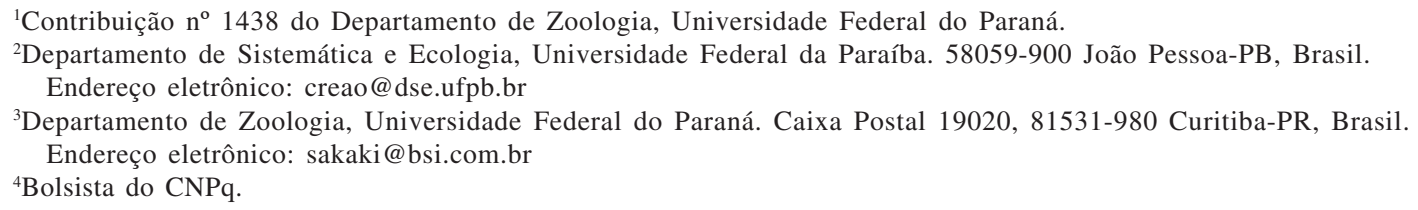

\begin{abstract}
Aвstract. New taxa in Membracinae (Hemiptera, Membracidae). Five new species are described: in Hoplophorionini Goding, 1926 - Metcalfiella venezuelana sp. nov. (Venezuela, Lara); in Hypsoprorini Haupt, 1929 - Hypsoprorachis fossulata sp. nov. (Brazil, Minas Gerais), Hypsoprora gracilis sp. nov. (Brazil, Mato Grosso), H. laminata sp. nov. (Brazil, São Paulo), and H. adusta sp. nov. (Brazil, Bahia). Photographs of the holotypes are given.
\end{abstract}

KEywords. Hemiptera; Membracidae; new species; taxonomy.

Resumo. Cinco novas espécies são descritas: em Hoplophorionini Goding, 1926 - Metcalfiella venezuelana sp. nov. (Venezuela, Lara); em Hypsoprorini Haupt, 1929 - Hypsoprorachis fossulata sp. nov. (Brasil, Minas Gerais), Hypsoprora gracilis sp. nov. (Brasil, Mato Grosso), H. laminata sp. nov. (Brasil, São Paulo) e H. adusta sp. nov. (Brasil, Bahia). Fotografias dos holótipos são apresentadas.

Palavras-Chave. Hemiptera; Membracidae; novas espécies; taxonomia.

Dentro de Membracinae Rafinesque, a tribo Hoplophorionini Goding foi a que teve, recentemente, uma atenção especial: a maioria dos seus gêneros foi revisada, tanto por autores norteamericanos como brasileiros (McKAMEY \& DeITZ 1991, 1996; CREÃo-DuARTE \& SAKAKIBARA 1997a, b, c ). Apesar da revisão de Metcalfiella Goding, 1929, feita por McKAMEy \& Deitz (1991), encontramos uma espécie que não se enquadra em nenhuma das apresentadas no trabalho citado. Descrevêmo-la como nova mais adiante.

A tribo Hypsoprorini Haupt, por outro lado, está à espera de uma revisão taxonômica. STRÜMPEl (1972) e SAKAKIBARA (1977, 1978), contribuíram com algumas notas importantes sobre o gênero Notocera Amyot \& Serville, 1843, e descrição de espécies novas. Fonseca \& Diringshofen (1969), no trabalho que tratam de diversos táxons neotropicais, criaram Hypsoprorachis, um gênero monotípico próximo de Hypsoprora Stål, 1869 e de Notocera. SAKAKIBARA (1974) deu a conhecer mais uma espécie de Hypsoprorachis.

Acrescentamos à tribo Hypsoprorini mais quatro novas espécies brasileiras, uma em Hypsoprorachis Fonseca \& Diringshofen, 1969 e três em Hypsoprora Stål, 1869.

Todos os exemplares estudados (holótipos) estão depositados na Coleção de Entomologia Pe. J. S. Moure, Departamento de Zoologia, Universidade Federal do Paraná, Curitiba-PR, Brasil (DZUP).

Hoplophorionini Goding, 1926

Metcalfiella venezuelana sp. nov. (Figs. 1-2)

Holótipo macho. Medidas (em mm). Comprimento total,
11,40; comprimento do pronoto, 7,60; largura da cabeça, 3,04; distância entre os ângulos umerais, 5,00.

Coloração geral castanho-escura; cabeça com duas manchas amareladas, de forma mais ou menos oval, abaixo de cada ocelo; metopídio, logo acima da cabeça, com manchas claras pouco definidas, espalhadas até os ângulos umerais. Margens laterais do pronoto avermelhadas, interrompidas por duas manchas enegrecidas na metade distal. Pernas avermelhadas, especialmente as anteriores e médias, exceto o ápice das tíbias e os tarsos, enegrecidos. Tégminas enfumaçadas, translúcidas, com uma pequena mancha escura na base entre as veias $\mathrm{Me} \mathrm{Cu}$.

Cabeça relativamente pequena, com largura pouco mais da metade da distância entre os ângulos umerais. Vértice quadrangular, pouco mais largo que longo, levemente inchado no meio. Olhos semi-globulares, pouco salientes. Ocelos conspícuos situados sobre a linha imaginária que passa pelo centro dos olhos, mais próximos entre si do que dos olhos. Lóbulos suprantenais arredondados, com os bordos engrossados. Pós-clípeo pouco intumescido, fortemente recurvado; anteclípeo sub-cônico; rostro atingindo as coxas mesotorácicas.

Pronoto densamente piloso, com pontuação grossa e homogênea; dorso levemente elevado após os ângulos umerais; em vista dorsal, de forma triangular, com a carena média obsoleta, os ângulos umerais obtusos, arredondados, mas margens póstero-laterais sinuosas junto aos úmeros, ápice agudo, terminando pouco depois do final do clavo; a distância olho-gancho mesepimeral quase duas vezes o diâmetro do olho. 
Genitália. Edeago dilatado para o ápice, com uma coroa de dentículos dorsalmente perto do ápice. Parâmeros curvados distalmente em forma de gancho.

Fêmea. Desconhecida.

Holótipo macho. "VENEZUELA, Lara, X-1948, R. R. Costa leg." (DZUP).

Comentários. Esta espécie é semelhante à $M$. semitecta (Walker, 1858), conforme pode-se observar pelos desenhos apresentados por McKameY 1991 (fig. 15). Difere um pouco da espécie de Walker pelo tamanho ligeiramente maior e pela sua coloração mais escura, apresentando no vértice, duas manchas amareladas, arredondadas, uma abaixo de cada ocelo e, o metopídio, também, com uma faixa transversa, de contorno pouco definido, entre os ângulos umerais.

Hypsoprorini Haupt, 1929

\section{Hypsoprorachis fossulata sp. nov.} (Figs. 3-5)

Holótipo macho. Medidas (em mm). Comprimento total, 4,20; largura máxima da cabeça, 1,26; distância entre os ângulos umerais, 1,74 .

Coloração geral castanho-escura com variegado de amarelo-acinzentado, destacando, no processo posterior, um anel pré-apical desta cor. Tégminas opacas, castanho-escuras, com áreas translúcidas no final do clavo e no limbo apical. Pernas castanho-escuras, com os tarsos esbranquiçados. Parte inferior do tórax e abdômen, castanho-escura; placa subgenital amarelo-pálida.

Cabeça, em vista frontal, quase tão longa quanto larga, de superfície mais ou menos plana, densamente pontuada; margem superior do vértice largamente arqueada. Olhos semiglobulares, pouco salientes para os lados. Ocelos conspícuos, situados acima da linha imaginária que passa pelo centro dos olhos, mais próximos destes que entre si. Lóbulos supraantenais laminares, mais ou menos triangulares, com as margens laterais sinuosas. Pós-clípeo foliáceo, aconcavado, de forma aproximada de um pentágono, com os ângulos arrredondados, quase tão largo quanto longo; anteclípeo escondido atrás do pós-clípeo. Rostro atingindo as coxas posteriores.

Pronoto trituberculado, estendido posteriormente até o final das tégminas, grosseiramente pontuado e esparsamente coberto com pequenos tubérculos pilíferos; elevado acima da cabeça em um grande tubérculo, em vista lateral, ligeiramente inclinado para frente, com a parte superior truncada; em vista anterior, a altura do pronoto quase igual ao comprimento da cabeça, levemente constricto acima dos úmeros e com a parte superior distintamente trilobada; em vista superior, destacando-se quatro concavidades, ou fossetas, mais ou menos profundas, dispostas: duas no topo e duas posteriormente, separadas medianamente por uma lamela formada pela carena dorsal. Processo mediano bem desenvolvido, terminado em dois lobos ovóides. Processo posterior dilatado na altura do ápice do clavo, tanto para cima como lateralmente, com a parte posterior achatada, ligeiramente côncava; largura desta expansão menor que a largura da cabeça; porção terminal tectiforme, distintamente tricarenada.

Tégminas coriáceas e grosseiramente pontuadas na metade basal, o restante microcorrugado. Venação pouco distinta mas permitindo visualizar duas células discoidais e cinco apicais; $\mathrm{M}$ e $\mathrm{Cu}$ unidas na base; transversas $\mathrm{s}, \mathrm{r}-\mathrm{m}$ e duas $\mathrm{m}-\mathrm{cu}$ presentes. Asas posteriores hialinas, com quatro células apicais.

Fêmea desconhecida.

Holótipo macho, de "PIRAPORA-MG/ XI . 1977 - Moure/ e Sakakibara" (DZUP).

Comentários. Esta espécie é muito parecida com Hypsoprorachis bucki Sakakibara, 1974, isto é, os machos são semelhantes no tamanho e na forma do pronoto (as fêmeas são desconhecidas). As diferenças marcantes são: $H$. buckias quatro fossetas da elevação anterior são dispostas duas a duas no topo, no mesmo plano, cada qual com o contorno circular; processo posterior com a expansão de largura pouco

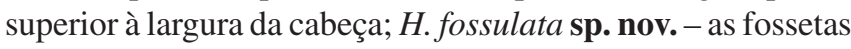
da elevação anterior dispostas, duas no topo e duas na face posterior, cada qual com o contorno mais ou menos elíptico; processo posterior com a expansão de largura inferior à largura da cabeça.

O nome da espécie refere-se à presença das concavidades ou fossetas, na elevação anterior do pronoto.

\section{Hypsoprora gracilis sp. nov.}

(Figs. 6-7)

Holótipo fêmea. Medidas (em mm). Comprimento total, 6,00; largura máxima da cabeça, 1,28; distância entre os ângulos umerais, 1,60.

Coloração geral castanho-clara, amarelada; parte inferior do corpo castanho-escura.

Cabeça, em vista frontal, pouco mais larga que longa, ligeiramente convexa, finamente pontuada; margem superior do vértice largamente arqueada. Olhos semi-globulares, pouco salientes para os lados. Ocelos conspícuos, situados logo acima da linha imaginária que passa pelo centro dos olhos, mais próximos destes que entre si. Lóbulos suprantenais triangulares com os bordos ligeiramente sinuados. Pós-clípeo foliáceo, de contorno arredondado distalmente, pouco mais longo que largo, no mesmo plano do vértice; anteclípeo escondido atrás do pós-clípeo. Rostro atingindo as coxas posteriores.

Pronoto delgado, afilado em ambas as extremidades; processo anterior obliquamente projetado à frente da cabeça, 


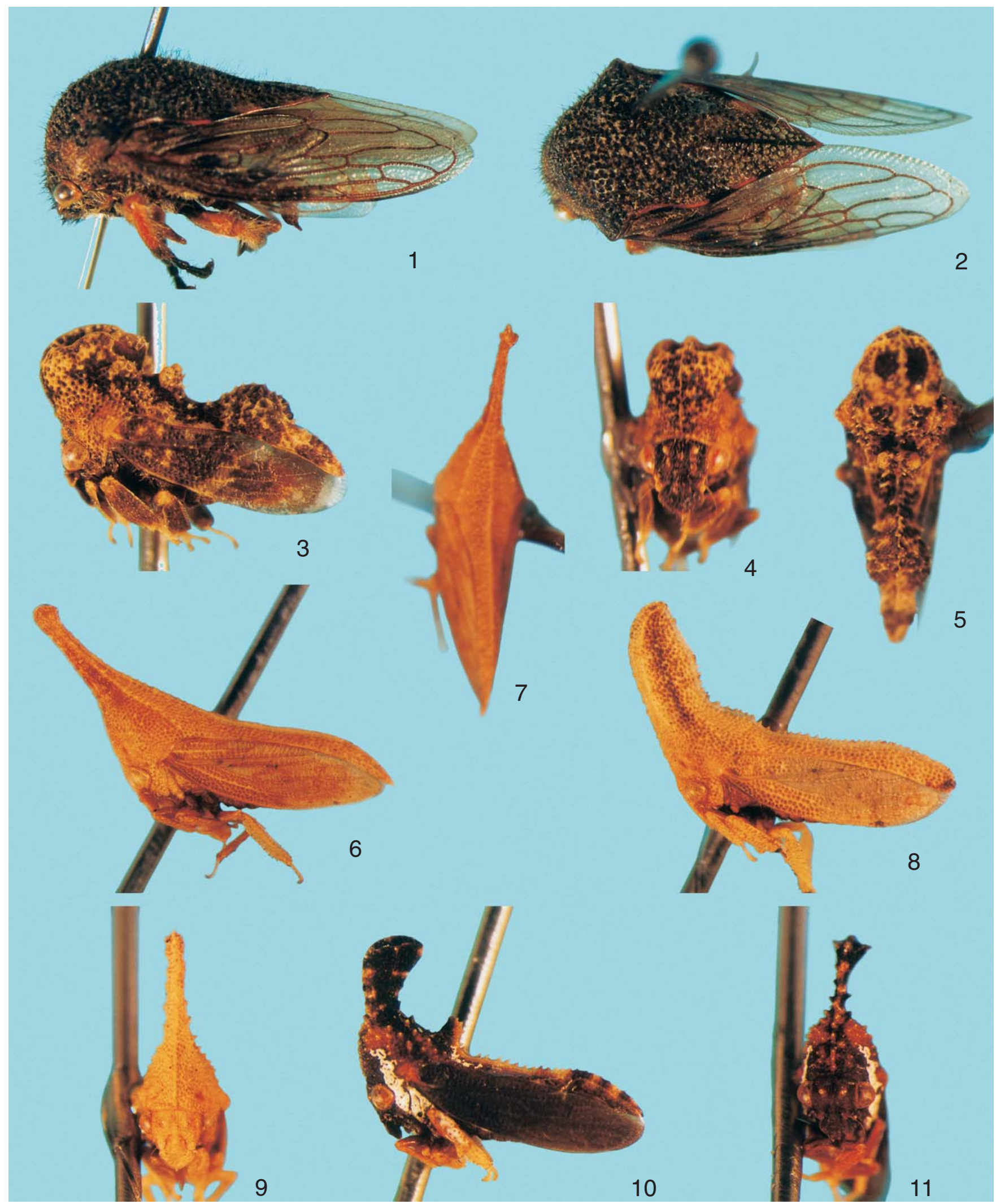

Figs. 1-11. Fotos dos holótipos: 1-2, Metcalfiella venezuelana sp. nov.; 3-5, Hypsoprorachis fossulata sp. nov.; 6-7, Hypsoprora gracilis sp. nov.; 8-9, Hypsoprora laminata sp. nov.; 10-11, Hypsoprora adusta sp. nov. 
gradativamente afilado para o ápice, apenas ligeiramente dilatado pouco antes da sua ponta romba; margens laterais providas de duas tênues carenas longitudinais unidas perto do ápice e divergentes para baixo: a anterior evanescente na altura do metopídio e, a posterior, quase alcançando a margem lateral, logo atrás do úmero. Carena média dorsal bem evidente, mais ou menos serrilhada na parte posterior do processo anterior. Processo posterior tectiforme, delgado, de contorno regular desde o ápice do processo anterior e acompanhando a curvatura das tégminas e terminando pouco além do ápice das mesmas.

Tégminas opacas, coriáceas e pontuadas na metade basal; duas células discoidais e cinco apicais; $\mathrm{M}$ e $\mathrm{Cu}$ unidas na base; transversas s, $\mathrm{r}-\mathrm{m}$ e duas $\mathrm{m}$-cu presentes.

Macho desconhecido.

Holótipo fêmea, de "VILA VERA-MT/ Brasil - X . 1974/ M. Alvarenga" (DZUP).

Comentários. Esta espécie difere das outras congêneres por apresentar o pronoto delgado, sem a expansão distal do processo anterior e, também, sem a elevação mediana. Estas características fazem lembrar os representantes do gênero Philya Walker, 1858.

O nome da espécie é alusivo ao pronoto fino e delicado.

\section{Hypsoprora laminata sp. nov.}

(Figs. 8-9)

Holótipo fêmea. Medidas (em mm). Comprimento total, 5,80; largura máxima da cabeça, 1,20; distância entre os ângulos umerais, 1,56.

Semelhante à espécie anterior quanto à sua coloração e características gerais.

Pronoto com o processo anterior obliquamente elevado acima da cabeça, fortemente comprimido lateralmente, de aspecto laminar, arredondado no ápice e ligeiramente recurvado; lateralmente provido de duas carenas longitudinais: a anterior bem pronunciada em direção ao ápice e , a posterior, medíocre, pouco visível. Elevação mediana obsoleta, visível apenas de lado, em forma de uma pequena saliência da carena média dorsal. Processo posterior delgado, em vista lateral com os bordos mais ou menos paralelos até quase a ponta, este ultrapassando levemente as tégminas. Carena média dorsal serrilhada desde o ápice do processo anterior.

Macho desconhecido.

Holótipo fêmea, de "S. Bocaina 1650m/ S. J. Barreiro-SP/ Brasil I1969/ M. Alvarenga" (DZUP).

Comentários. Parecida com a espécie precedente, porém, com o processo anterior bem mais largo e foliáceo, mais de duas vezes mais largo que o processo posterior. A carena média dorsal é inteiramente serrilhada, sendo mais evidente depois do ápice do processo anterior.

O nome da espécie é alusivo à forma laminada do processo anterior.

\section{Hypsoprora adusta sp. nov.}

(Figs. 10-11)

Holótipo macho. Medidas (em mm). Comprimento total, 4,32; largura máxima da cabeça, 1,10; distância entre os ângulos umerais, 1,40 .

Coloração geral castanho-escura, principalmente a cabeça, metopídio, parte distal do processo anterior e do processo posterior, face ventral do corpo e tégminas; grande parte do pronoto irregularmente manchado de castanho-claro e amarelopálido. Uma faixa branco-cerosa, de cada lado do pronoto desde o metopídio até os lóbulos pós-oculares e, depois, estendendo-se por sobre as pleuras mesotorácicas e, também, sobre as tíbias posteriores em sua face externa. Pernas castanho-amareladas.

Características básicas semelhantes às demais espécies.

Pronoto elevado acima da cabeça e fortemente constrito no meio, depois achatado lateralmente e expandido para o ápice; em vista lateral, obliquamente truncado na ponta, com o ângulo posterior projetado para trás; em vista anterior, terminado em uma pirâmide invertida, distintamente tricarenada no topo. Elevação média bem pronunciada, cônica, tão larga quanto alta. Processo posterior delgado, ligeiramente dilatado na altura do ângulo interno das tégminas, terminando junto com o ápice das mesmas. Carena média dorsal fortemente serrilhada, principalmente na base do processo posterior.

Fêmea desconhecida.

Holótipo macho de "ENCRUZILHADA-BA, 980m/ Motel divisaX. 1974/ Alvarenga-Seabra leg." (DZUP).

Comentários. A forma geral do pronoto é comum à de várias espécies do gênero. A que mais se aproxima é $H$. coronata (Fabricius, 1803) que tem o processo anterior fortemente constrito acima do metopídio e com a porção apical dilatada e recurvada. Em H. adusta sp. nov., o processo anterior é menos constrito e menos curvado para trás, aproximandose, neste aspecto, de H. expansa Sakakibara, 1978.

O nome da espécie é alusivo ao colorido geral que o exemplar apresenta, de aspecto chamuscado (adustus $=$ queimado).

\section{REFERÊNCIAS}

Creão-Duarte, A. J. \& A. M. Sakakibara. 1997a ["1996"]. Revisão do gênero Umbonia Burmeister (Homoptera, Membracidae, Membracinae, Hoplophorionini). Revista Brasileira de Zoologia 13(4): 973-994.

Creão-Duarte, A. J. \& A. M. Sakakibara. 1997b [“1996"]. Revisão do 
gênero Potnia Stål (Homoptera, Membracidae, Membracinae, Hoplophorionini). Revista Brasileira de Zoologia 13(4): 10011021.

Creão-Duarte, A. J. \& A. M. Sakakibara. 1997c. Revisão de Alchisme Kirkaldy (Hemiptera, Membracidae, Membracinae, Hoplophorionini). Revista Brasileira de Zoologia 14(2): 425472.

Fonseca, J. P. Da \& R. V. Diringshofen. 1969. Contribuição ao conhecimento dos membracídeos neutrópicos (Homoptera: Membracidae, VI). Arquivos do Instituto Biológico 36 (3): 143161.

McKamey, S. H. \& L. L. Deitz. 1991. Revision of the Neotropical treehopper genus Metcalfiella (Homoptera: Membracidae). North Carolina State University. Technical Bulletin 294: 1-89.

McKamey, S. H. \& L. L. Deitz. 1996. Generic revision of the New World tribe Hoplophorionini (Hemiptera: Membracidae: Membracinae).
Systematic Entomology 21: 295-342.

SaKakibara, A. M. 1974. Sobre o gênero Hypsoprorachis Fonseca \& Diringshofen, 1969, com descrição de uma espécie nova (Homoptera, Membracidae). Revista Brasileira de Entomologia 18 (2): 51-54.

SAKAKIBARA, A. M. 1977. Algumas observações sobre Notocera brachycera (Fairmaire) e descrição de uma nova espécie (Homoptera, Membracidae). Dusenia 10(1): 31-36.

Sakakibara, A. M. 1978. Três novas espécies de Hypsoprora Stål (Homoptera, Membracidae). Revista Brasileira de Entomologia 22(2): 77-82.

StrüMPel, H. 1972. Die Membraciden-Fauna Kolumbiens. 1. Die Gattung Notocera Amyot \& Serville, 1843. Mitteilungen aus dem Hamburgischen Zoologischen Museum Institut 69 (33-58): 33-58. 